\title{
NUMERICAL ANALYSIS FOR SMOKE SPREAD IN AN AIRCRAFT HANGAR
}

\author{
Essam E. Khalil ${ }^{1}$, Hatem Kayed Haridy ${ }^{2}$, Eslam Said Abdelghany Ahmed ${ }^{3}$ and Ahmed Ashraf Mohamed ${ }^{4}$ \\ ${ }^{1,2}$ Mechanical Power Department, Faculty of Engineering - Cairo University, Egypt \\ ${ }^{3,4}$ Mechanical Power Department, Faculty of Engineering - IAET, Egypt
}

\begin{abstract}
Smoke is one of the most dangerous factors in aircraft hangar in case of fire. As it causes reduce in visibility and deaths due to high temperature or toxicity also prevents applying evacuation plan for workers. This study present numerical analysis for improving traditional system of ventilation system to manage smoke produced due to push-back vehicle on fire at hangar. By studying effect of changing extraction and supply rates, the number of extraction and supply fans, and the arrangement of extraction and supply fans on the visibility, temperature and air velocity at human level to insure not to exceed limits stated by NFPA 130[1] to apply evacuation plan for workers. The study is performed using Fire dynamic simulator to simulate 16 case studies in the hangar of airports in Brandenburg. The hangar has the outer dimensions of $83.40 \mathrm{~m}$ width and $77.60 \mathrm{~m}$ depth and thus an inner area of approx. $6,472 \mathrm{~m} 2$. The hangar has a medium interior height of approximately $18.20 \mathrm{~m}$. The results show that using extraction fans with rate $(\mathrm{ACH})$ double the supply rate for the traditional ventilation system gives very good results in controlling the smoke. As well as, decreasing the number of supply fans will make the smoke spread rate inside the hangar lower, which helps to control the smoke spread of fire in less time.
\end{abstract}

Key Words: Aircraft Hangar, ventilation, smoke control, Fire Dynamics Simulator.

\section{Introduction}

Aircraft hangars, by their very nature, pose a unique challenge for fire safety engineers. Large, open floored areas with high roof decks house aircraft contents worth millions of dollars [2]. In addition to the large amounts of jet fuel, a number of the maintenance activities that take place within hangars provide a host of ignition sources. Once the fire breaks out, a lot of smoke is produced with high temperature results in poor leakage ability and difficulties in evacuation. Large aircraft wings, fuselages and scaffolding also have the potential to restrict fire detection, suppression and the flow of smoke, presenting a potentially lethal cocktail. For fire safety design to be effective, a number of issues must first be considered. These include fire source, heat transfer, fire detection and alarm, human behavior, smoke movement, toxicity and pollution. Smoke management aims to extract the smoke produced from fire by means of ventilation systems in order to provide safe escape by extending the evacuation time for the occupants, improving building conditions which assist firefighters to detect fire place and start firefighting, protecting valuable objects from fire, and hence reduce the probability of fire-extension to the whole area and reducing the risk of explosion. Smoke management can be classified into two main systems.

First, Natural Ventilation; depends on convection currents, wind, and other natural air movement to allow contaminated atmosphere to flow out of a structure. The heat of a fire creates convection currents that move smoke and gases up toward the roof or ceiling and out and away from the fire source. Opening or breaking a windows or door allows these products of combustion to escape through natural ventilation. Natural ventilation can be used only when the natural convection air currents or wind are adequate to move the contaminated atmosphere out of the building and replace it with fresh air.

Second, Mechanical (Forced) ventilation; used when natural forces do not provide adequate ventilation. There are three different methods of mechanical ventilation. Negative- pressure ventilation uses fans called smoke ejectors to exhaust smoke and hear from structure. Positive-pressure ventilation uses fans to introduce clean air into a structure and push the contaminated atmosphere out. Hydraulic ventilation moves air by using fog or broken-pattern fire streams to create a pressure differential behind and in front of the nozzle. In large buildings, negative-pressure ventilation can be used to pull heat out of the building, particularly if natural ventilation would be too slow or if no natural cross- ventilation exits.

Impulse ventilation, recently jet fans or impulse fans have established itself as the new standard in ventilation. IVS are an alternative choice to ducted mechanical extract systems. A series of jet fans are distributed beneath the ceiling, produce air movement from the air inlet openings towards pre-designated extract points, transferring smoke and fumes with it. 


\section{CFD Modeling}

\subsection{Physical Model}

The air-craft hangar under analysis is a real hangar located in Brandenburg-Germany. The hangar has the outer dimensions of $83.40 \mathrm{~m}$ width and $77.60 \mathrm{~m}$ depth and thus an inner area of approx. $6,472 \mathrm{~m} 2$. The hangar has a medium interior height of approximately $18.20 \mathrm{~m}$. Equipped with mechanical exhaust system to exhaust smoke in case of fire. The computational domain used in the case study has the same dimensions of the actual hangar as shown in figure 1. The Push-back vehicle on fire is located at the top left corner -beside door- of the computational domain; it is modeled by a block of a 5.83 $\mathrm{m}$ long, $2.4 \mathrm{~m}$ wide and $2 \mathrm{~m}$ high. The fire development is confined to a steady phase fire and a peak value of $4 \mathrm{MW}$ [3]. Soot formation is a very complex process affected by many factors, for example, fuel type, fuel size and fire environment. Soot yield is given as 0.05 , as a medium value [4]. The ceiling and the floor were set to be concrete. Block representing push-back vehicle on fire was set to be steel. The properties of these two materials were just set according to the database of FDS. Ambient temperature is considered $35^{\circ} \mathrm{C}$ [5]. Four exhaust fans are suggested to be installed at the ceiling plus twelve supply fans six on each side as shown in figure 2. Simulation case studies as well as four fire scenarios are shown in table 1.

Table 1: Case Studies and fire scenarios

\begin{tabular}{|c|c|c|c|c|c|c|c|}
\hline \multirow{2}{*}{$\begin{array}{c}\text { Case } \\
\text { Number }\end{array}$} & \multirow{2}{*}{$\begin{array}{l}\text { Fire Location } \\
(\mathbf{X}, \mathbf{Y}, \mathbf{Z})\end{array}$} & \multicolumn{3}{|c|}{ Supply } & \multicolumn{3}{|c|}{ Extraction } \\
\hline & & $\begin{array}{c}\text { Rate } \\
(\mathrm{ACH})\end{array}$ & $\begin{array}{c}\text { No. of } \\
\text { fans }\end{array}$ & Position & $\begin{array}{c}\text { Rate } \\
(\mathrm{ACH})\end{array}$ & $\begin{array}{l}\text { No. of } \\
\text { fans }\end{array}$ & Position \\
\hline 1 & $(3.415,1.5,1.7)$ & 10 & 12 & \multirow{13}{*}{ 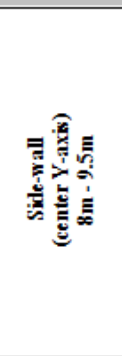 } & 10 & 4 & \multirow{14}{*}{ 跑 } \\
\hline 2 & $(3.415,1.5,1.7)$ & 10 & 12 & & 20 & 4 & \\
\hline 3 & $(3.415,1.5,1.7)$ & 10 & 12 & & 10 & 12 & \\
\hline 4 & $(3.415,1.5,1.7)$ & 10 & 12 & & 20 & 12 & \\
\hline 5 & $(3.415,1.5,1.7)$ & 10 & 12 & & 10 & 8 & \\
\hline 6 & $(3.415,1.5,1.7)$ & 10 & 12 & & 20 & 8 & \\
\hline 7 & $(3.415,1.5,1.7)$ & 10 & 12 & & 10 & 6 & \\
\hline 8 & $(3.415,1.5,1.7)$ & 10 & 12 & & 20 & 6 & \\
\hline 9 & $(3.415,1.5,1.7)$ & 20 & 12 & & 20 & 6 & \\
\hline 10 & $(3.415,1.5,1.7)$ & 10 & 16 & & 20 & 6 & \\
\hline 11 & $(3.415,1.5,1.7)$ & 20 & 16 & & 20 & 6 & \\
\hline 12 & $(3.415,1.5,1.7)$ & 20 & 10 & & 20 & 6 & \\
\hline *13* & $(3.415,1.5,1.7)$ & 10 & 10 & & 20 & 6 & \\
\hline 14 & $(3.415,1.5,1.7)$ & 10 & 10 & $\begin{array}{c}\text { Side-wall } \\
\text { (center Y-axis) } \\
1.5 \mathrm{~m}-3 \mathrm{~m} \\
\end{array}$ & 20 & 6 & \\
\hline 15 & $(3.415,1.5,1.7)$ & 10 & 10 & \multirow{2}{*}{$\begin{array}{l}\text { Side-wall } \\
\text { (center Y-axis) } \\
8 m-9.5 m\end{array}$} & 20 & 6 & \multirow{2}{*}{ 麓 } \\
\hline 16 & $(3.415,1.5,1.7)$ & 10 & 10 & & 20 & 6 & \\
\hline $\begin{array}{c}\text { Fire } \\
\text { Scenario } \\
1\end{array}$ & $(3.415,1.5,1.7)$ & 10 & 10 & \multirow{4}{*}{ 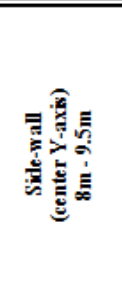 } & 20 & 6 & \multirow{4}{*}{ 麓 } \\
\hline $\begin{array}{c}\text { Fire } \\
\text { Scenario } \\
\mathbf{2}\end{array}$ & $(79.985,1.5,1.7)$ & 10 & 10 & & 20 & 6 & \\
\hline $\begin{array}{c}\text { Fire } \\
\text { Scenario } \\
3 \\
\end{array}$ & $(3.415,1.5,75.9)$ & 10 & 10 & & 20 & 6 & \\
\hline $\begin{array}{c}\text { Fire } \\
\text { Scenario } \\
4\end{array}$ & $(79.985,1.5,75.9)$ & 10 & 10 & & 20 & 6 & \\
\hline
\end{tabular}
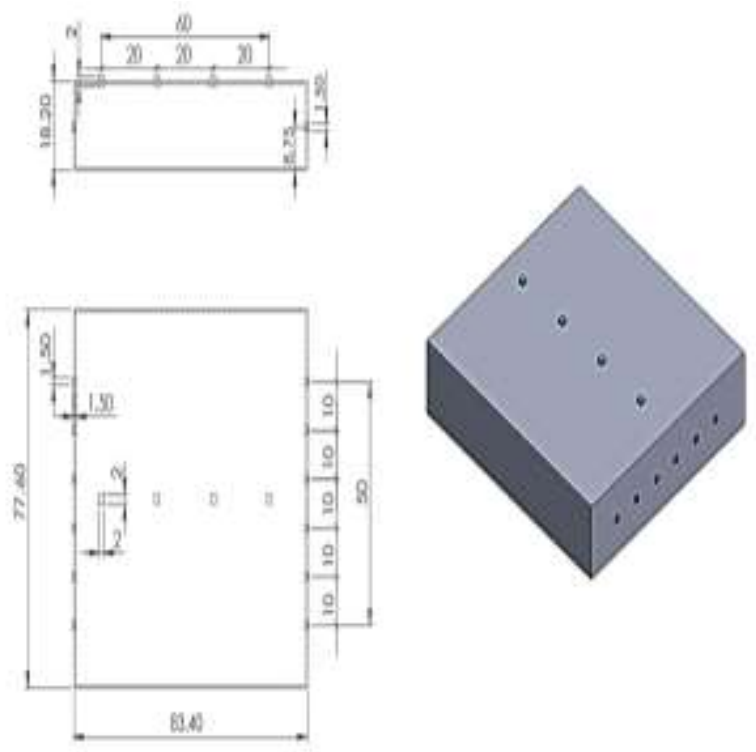

Fig. 1. Hangar dimensions

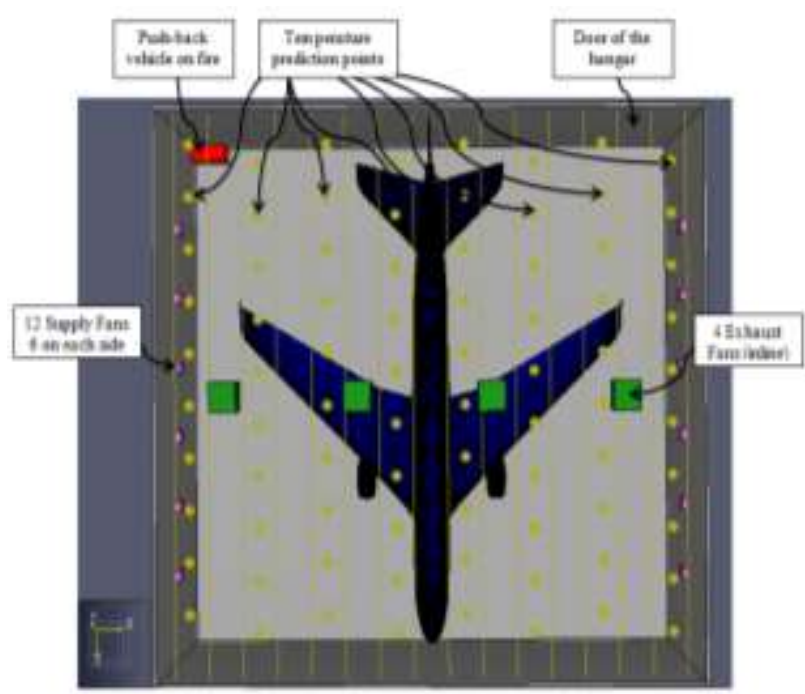

Fig. 2. Computational Domain

\subsection{Governing Equations}

With the fast development of computer technology, computational fluid dynamics (CFD) simulation has been becoming an important means of engineering calculations of fluid motion and ventilation. Fire dynamics simulator (FDS) developed by National Institute of Standards and Technology (NIST) is a popular (CFD) model for fire scenario simulation. Turbulence is treated by means of the Smagorinsky form of Large Eddy Simulation (LES). It is possible to perform a Direct Numerical Simulation (DNS) if the underlying numerical grid is fine enough. LES is used in the present work. Mass conservation can be expressed either in terms of the density, $\rho$, 
Mass conservation can be expressed either in terms of the density, $\rho$,

$\frac{\partial \rho}{\partial \mathrm{t}}+\nabla \cdot \rho \mathrm{U}=\dot{\mathrm{m}}_{\mathrm{b}}^{\prime \prime \prime}$

or in terms of the individual gaseous species, $\mathrm{Y}_{\alpha}$ :

$\frac{\partial}{\partial \mathrm{t}}\left(\rho \mathrm{Y}_{\alpha}\right)+\nabla \cdot \rho \mathrm{Y}_{\alpha} \mathrm{U}=\nabla \cdot \rho \mathrm{D}_{\alpha} \nabla \mathrm{Y}_{\alpha}+\dot{\mathrm{m}}_{\alpha}^{\prime \prime \prime}+\dot{\mathrm{m}}_{\mathrm{b}, \alpha}^{\prime \prime \prime}$

The momentum equation in conservative form is written:

$\frac{\partial}{\partial t}(\rho U)+\nabla \cdot \rho U U+\nabla p=\rho g+f_{b}+\nabla \cdot \tau_{i j}$

The energy conservation equation is written in terms of the enthaply $h_{s}$ as

$\frac{\partial}{\partial \mathrm{t}}\left(\rho \mathrm{h}_{\mathrm{s}}\right)+\nabla \cdot \rho \mathrm{h}_{\mathrm{s}} \mathrm{U}=\frac{\mathrm{Dp}}{\mathrm{Dt}}+\dot{\mathrm{q}}^{\prime \prime \prime}-\dot{\mathrm{q}}_{\mathrm{b}}^{\prime \prime \prime}-\nabla \cdot \dot{\mathrm{q}}^{\prime \prime}+\varepsilon(4)$

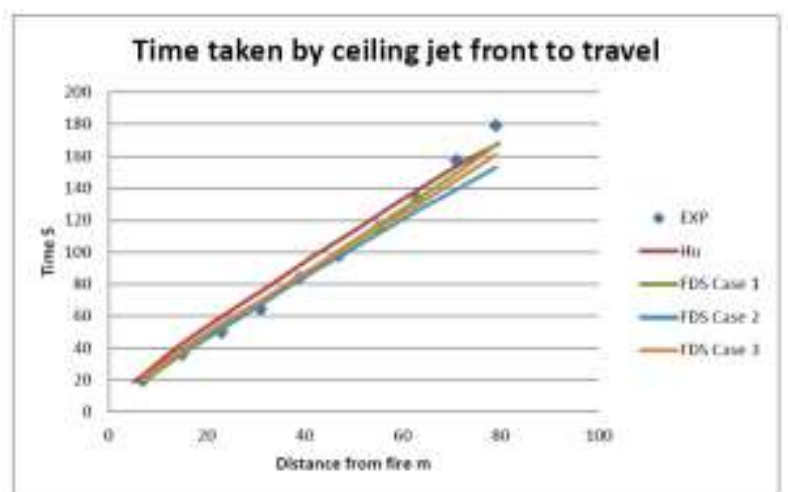

Fig.3. Comparison of Maximum ceiling jet temperature between FDS simulations and $\mathrm{Hu}$ experiment.

\section{Results And Discussion}

Visibility, temperature and velocity contours are simulated at human level $(1.8 \mathrm{~m})$ as the suitable condition for applying the evacuation plan is that the visibility should not be less than $10 \mathrm{~m}$, temperature not higher than $60 \mathrm{C}$ and air speed less than $11 \mathrm{~m} / \mathrm{s}$ according to NFPA 130 [1].

\subsection{Visibility}

The effect of changing extraction rate, number of extraction fans, arrangement of extraction fans, supply rate, number of supply fans and arrangement of supply fans on visibility are studied, to insure not to exceed limits stated by NFPA 130 [1] to find the most optimum design.

Case 1 and case 2 shows the effect of duplicating the smoke extraction rate for 4 extraction fans, Case 3 and case 4 shows the effect of duplicating the smoke extraction rate for 12 extraction fans, Case 5 and case 6 shows the effect of duplicating the smoke extraction rate for 8 extraction fans, Case 7 and case 8 shows the effect of duplicating the smoke extraction rate for 6 extraction fans, as shown in figure 4 and figure 5 . They show that duplicating the smoke extraction rate have a good effect on visibility.

\subsection{Validation of FDS}

$\mathrm{Hu}$ et al [6] performed Two full scale experiments with fire sizes of $0.75 \mathrm{MW}$ and $1.6 \mathrm{MW}$ were done in a $88 \mathrm{~m}$ long channel to study the smoke temperature distribution along the channel, the time taken for ceiling jet front to travel and the push-back carbon monoxide concentration at an assigned position. Comparisons are shown in Figure 3. The validation for FDS and grid sensitivity analysis is done by using experiment of $\mathrm{Hu}[6]$ and its correction [7] on long channel. The internal boundary material of the simulated channel was set to be same as that in the experiments. The ceiling was set to be gypsum. The side wall and the floor were set to be concrete. Steel board was set to be steel. The properties of these two materials were just set according to the database of FDS. The south end half-opened is modeled as an open vent to ambient at $27.5^{\circ} \mathrm{C}$. The simulation domain was $88 \mathrm{~m}$ long, $8 \mathrm{~m}$ wide and $2.7 \mathrm{~m}$ high. The space between 2.65 and $2.7 \mathrm{~m}$ was filled by gypsum. LES mathematical model for turbulence .The simulation time is taken as 600 seconds. Three cases are used with different grid cell number as shown in figure 3 .

Case 9 through case 13 shows the effect of changing the fresh air supply rate for 6 extraction fans with $20 \mathrm{ACH}$. Case 9 shows the effect of changing $\mathrm{ACH}$ of the supply fans to be the same as ACH of the extraction fans for the same number of supply fans.

While case 10 and 11 shows the effect of making the $\mathrm{ACH}$ of the supply fans half the ACH of extraction fans plus increasing the number of supply fans.

Case 12 and 13 shows the effect of making the $\mathrm{ACH}$ of the supply fans half and equals the $\mathrm{ACH}$ of extraction fans for 10 supply fans, as shown in figure 6 . It shows that duplicating the smoke extraction rate in addition to decreasing the supply fans to 10 have a good effect on visibility.

The effect of changing the position of supply fans is studied in case 14, as shown in figure 7 and it shows that changing the position of supply fans have a good effect on visibility. The effect of changing the arrangement of extraction fans also studied in case 15 (inverted honeycomb) and case 16 (staggered), they show that changing the arrangement of extraction fans have a good effect on visibility. 

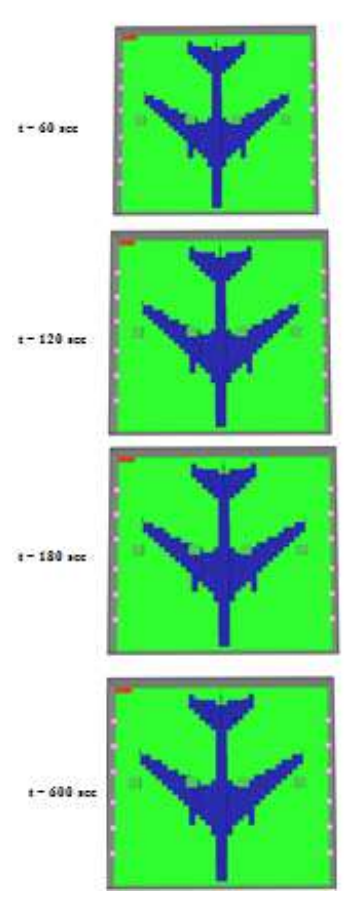

Case 1

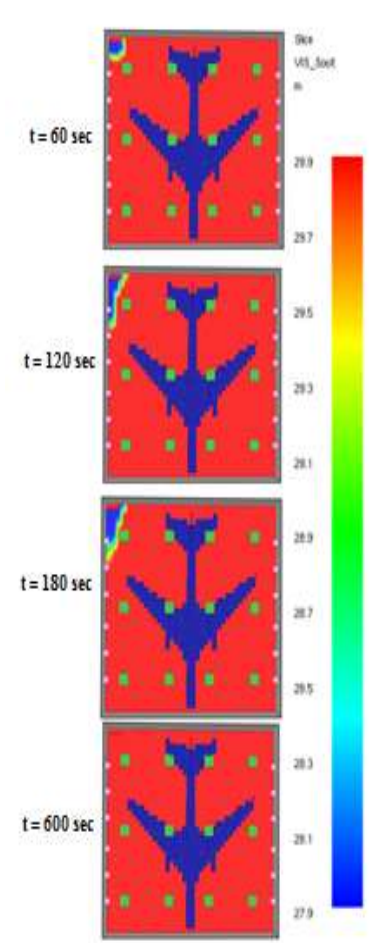

Case 3
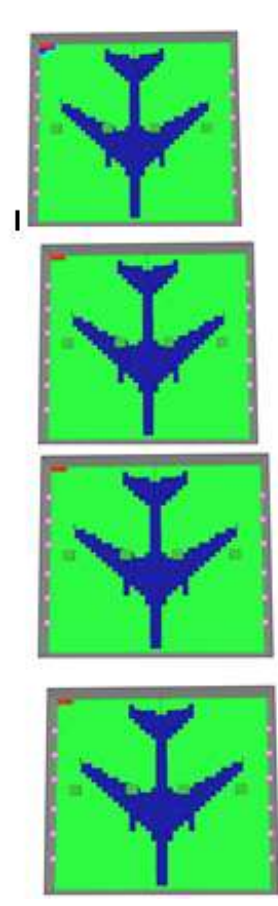

Case 2

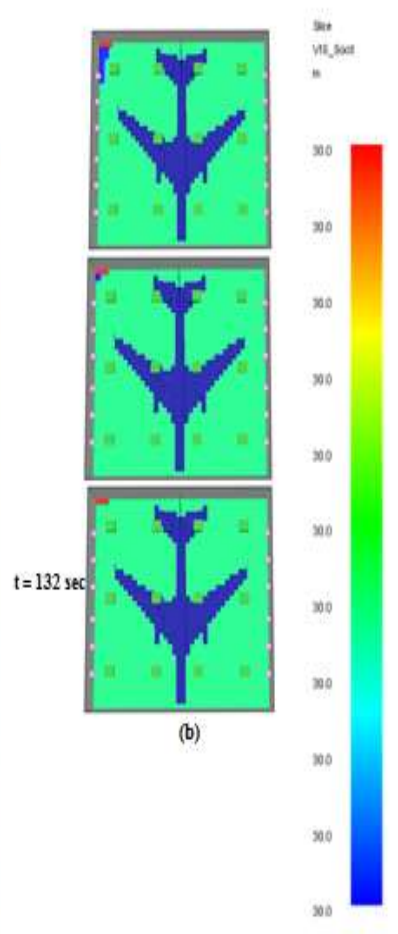

Case 4

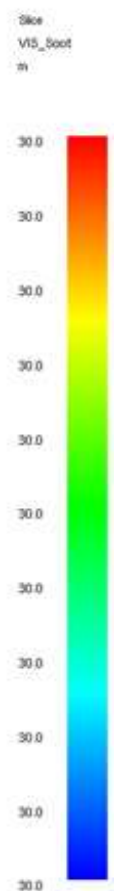

soo
Fig. 4.Visibility contours at human level at different times for Cases 1,2,3 and 4

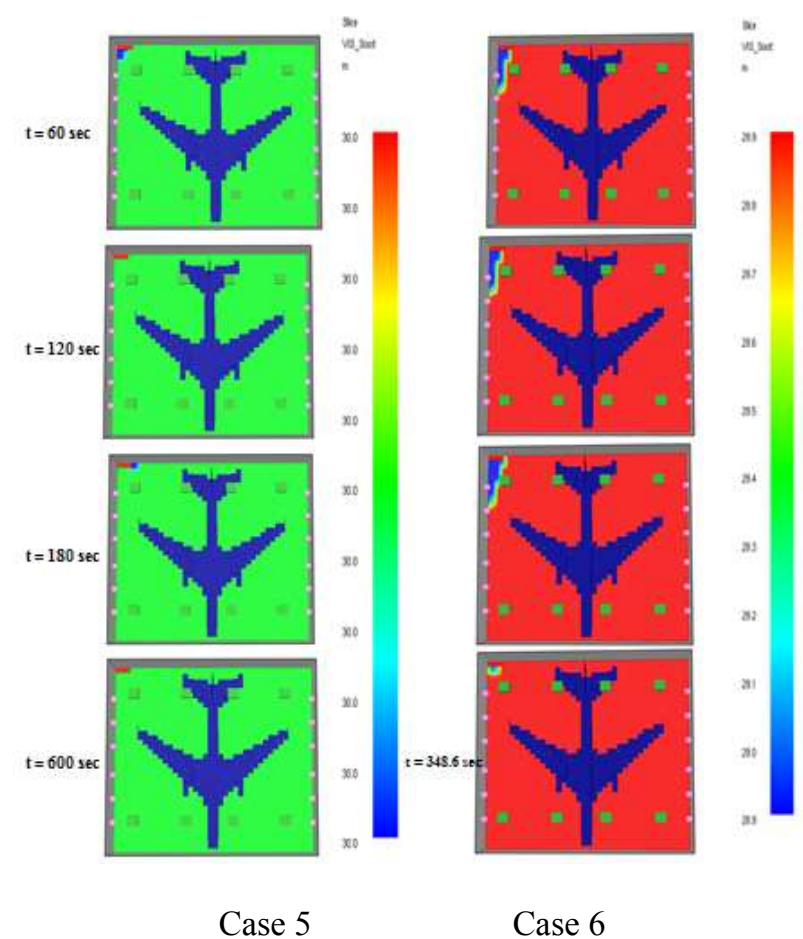

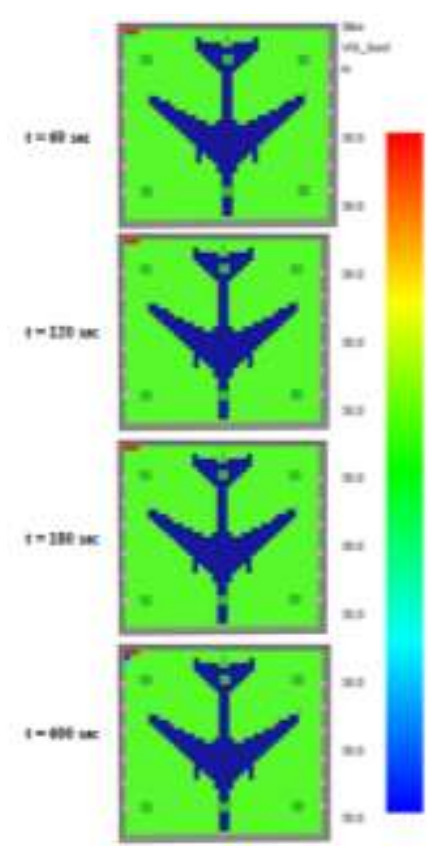

Case 7

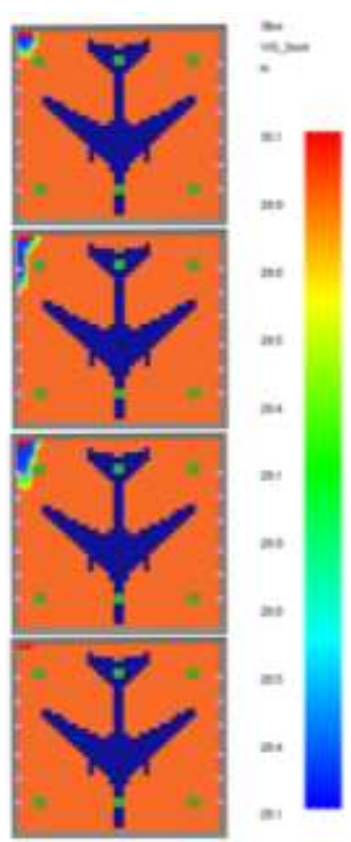

Case 8

Fig. 5. Visibility contours at human level at different times for Cases 5,6,7 and 8 

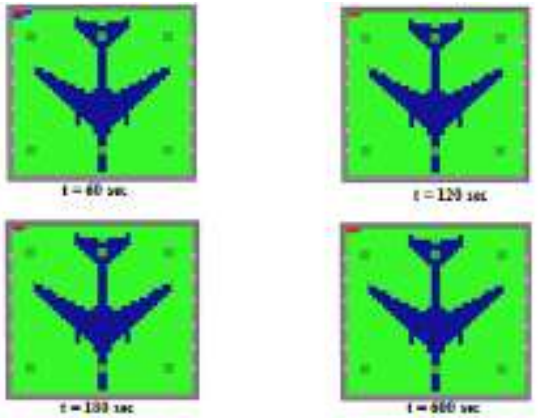

Case 9

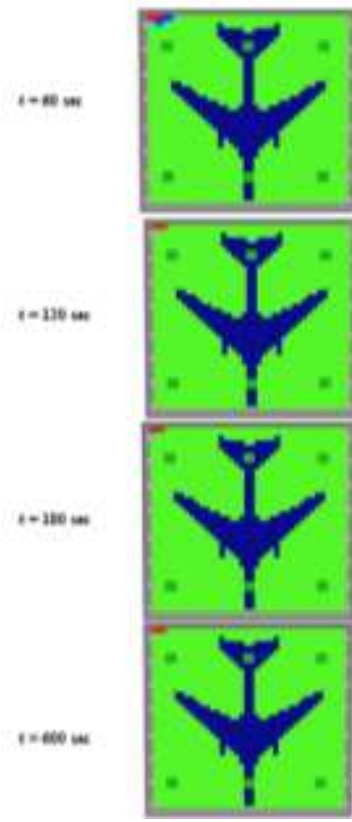

Case 10
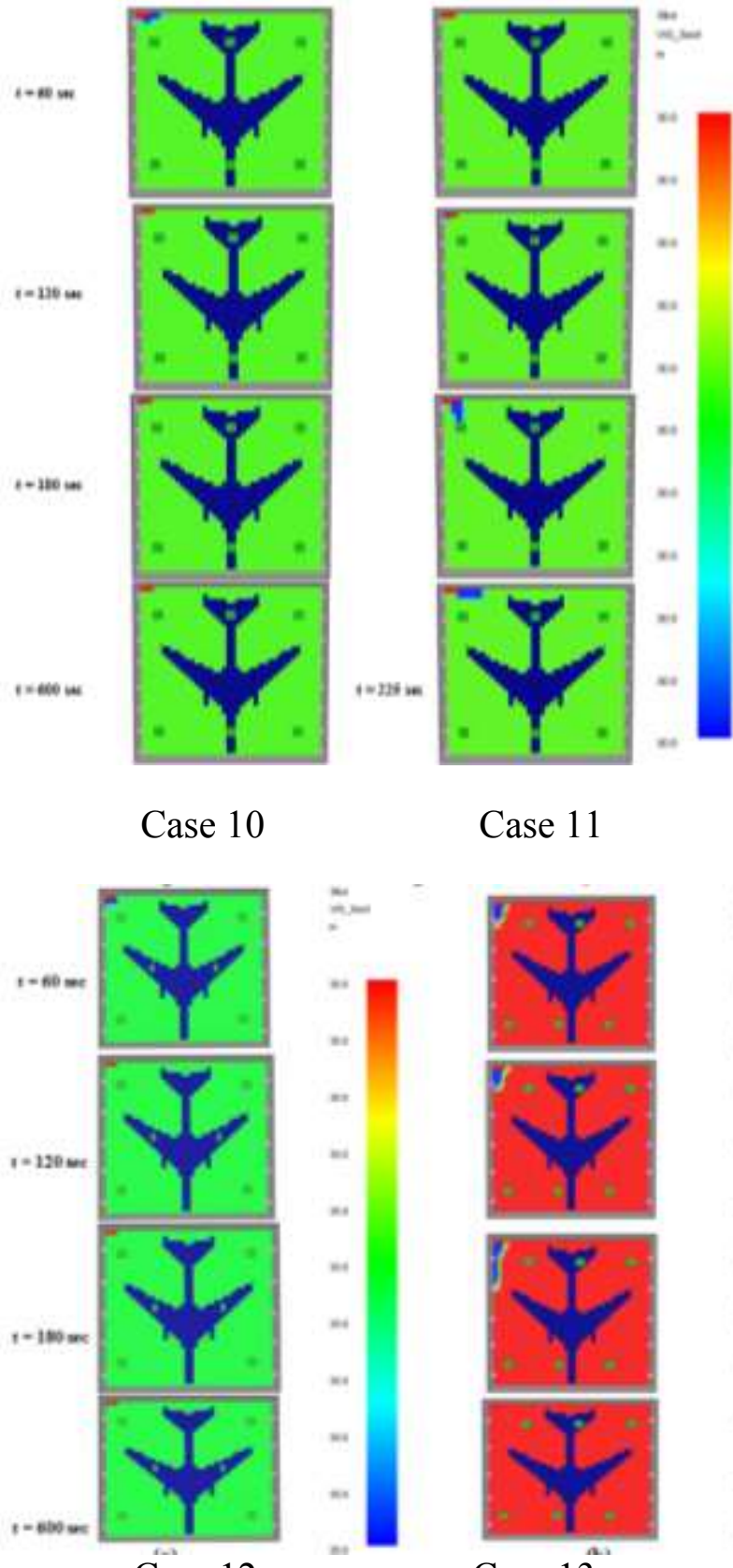

Case 12
Case 11
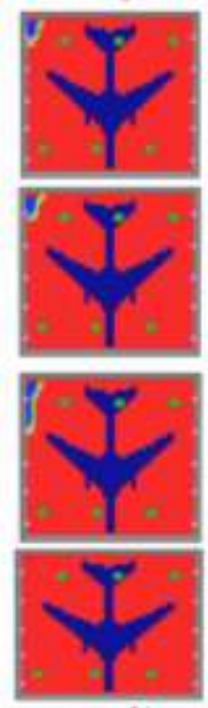

Case $13^{\circ}$

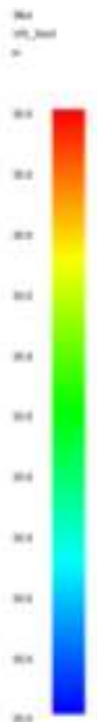

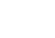

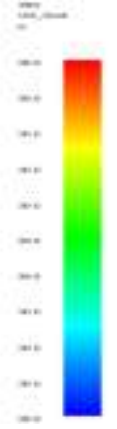

$+$
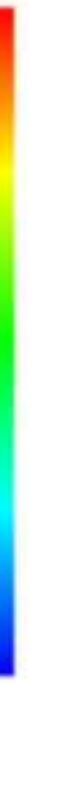

$=$
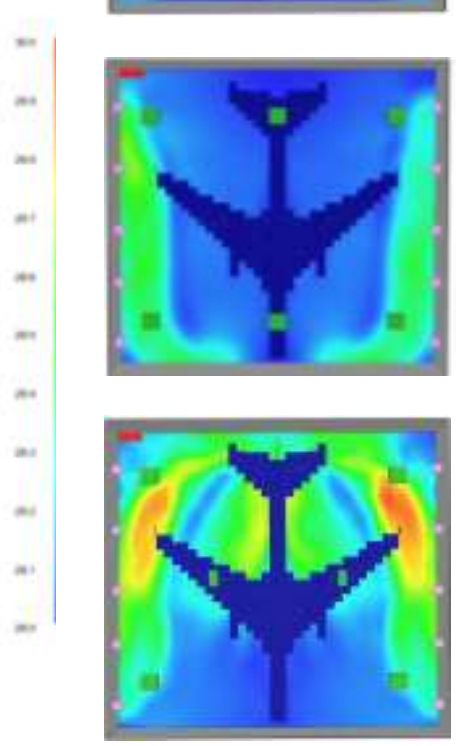
exceed $7.5 \mathrm{~m} / \mathrm{s}$.
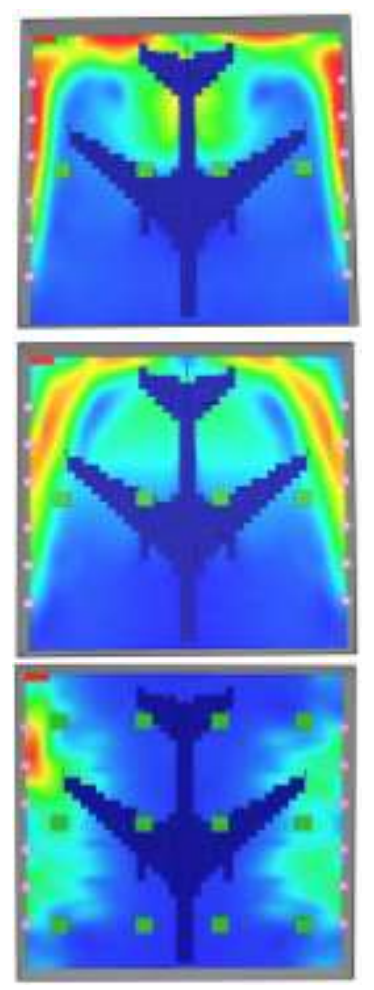

Case 1

Velocity at human level is one of the important parameter in designing smoke management system. The suitable condition for applying the evacuation plan is that the velocity must be less than $11 \mathrm{~m} / \mathrm{s}$ as stated by NFPA 130 [1]. Velocity slice is taken horizontally at human level $(\mathrm{Y}=1.8 \mathrm{~m})$ at certain sample time (60seconds) for some cases as shown in figure 7. All cases from show no great change in velocity all over the hangar; the maximum velocity at any point does not

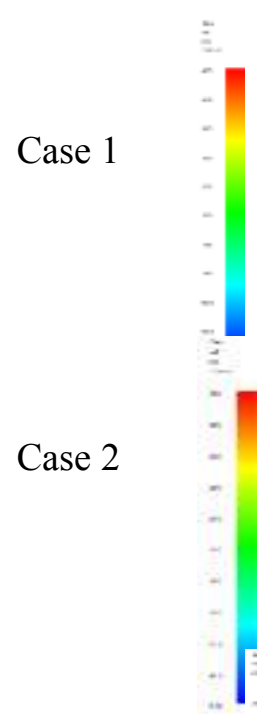

Case 3
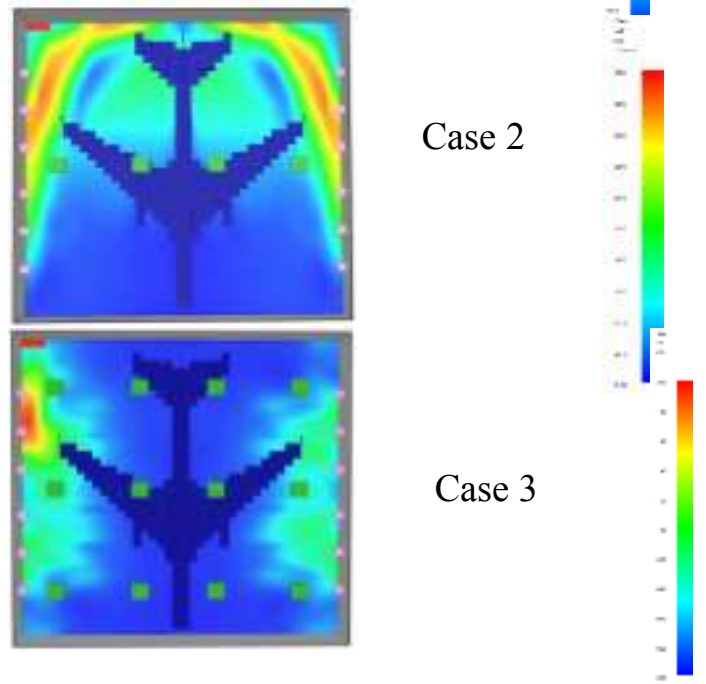

Case 13

Fig. 7. Air Velocity contours at human level at 60seconds.
Fig. 6. Visibility contours at human level at different times for Cases 9,10,11,12 and 13 


\subsection{Temperature}

Temperature increasing at human level is the third most critical parameter in designing smoke management system. The suitable condition for applying the evacuation plan is that temperature must be less than $60 \mathrm{oC}$ as stated by NFPA 130 [1]. Temperature slice is taken horizontally at human level $(\mathrm{Y}=1.8 \mathrm{~m})$ at certain sample time (600seconds) for some cases as shown in figure 8 .

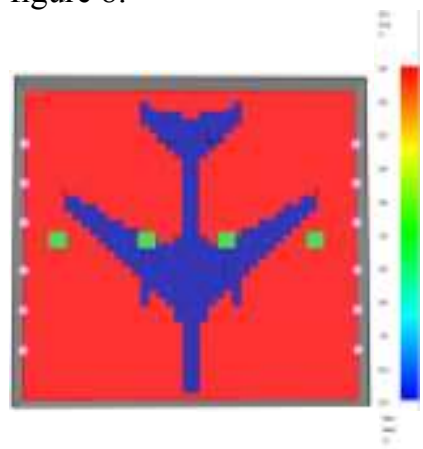

Case 1

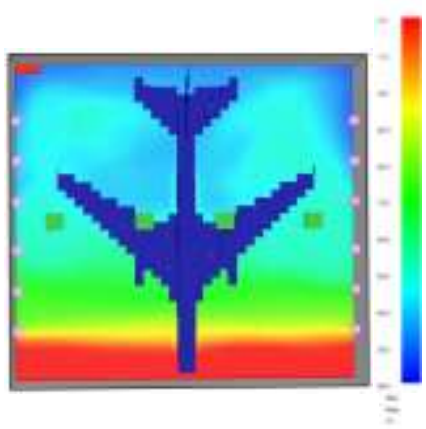

Case 2

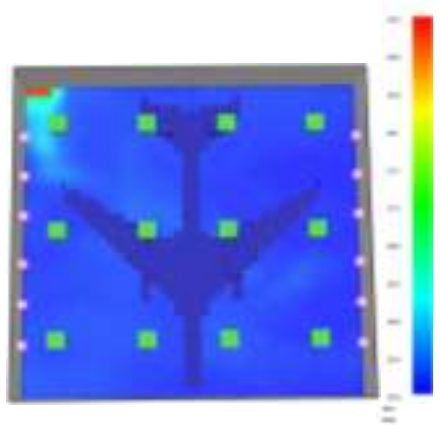

Case 3

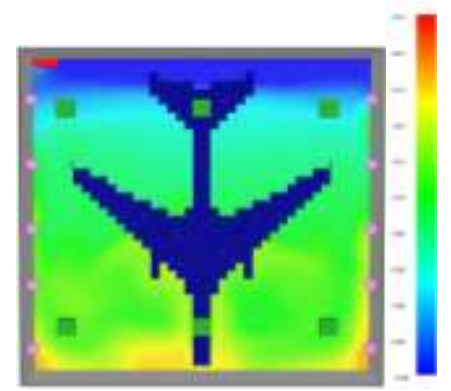

Case 13

Fig. 8. Temperature Distributions taken horizontally at human level $(\mathrm{Y}=1.8 \mathrm{~m})$ at $600 \mathrm{~s}$

For case 1; the system fails in extracting smoke at which temperature increases till reaches $625 \mathrm{oC}$. Case 2 ; there is an improvement in the temperature distribution, but it exceeds the limit stated by NFPA130 [1]. Case 3 records a great improvement in the temperature at human level. Case 13 shows a perfect temperature distribution during the 600 seconds duration. Case 15 is not too bad but it fails during the last minutes

\section{Concluding Remarks}

- FDS (Version 6.1.0) is a powerful tool for designing VS in hangars and service areas as it can import airplanes with actual dimensions and materials then predict smoke spread, temperature and velocity.

- Traditional ventilation system with some modifications can increase its effective in smoke extraction.

- Using extraction fans with rate $(\mathrm{ACH})$ double the supply rate for the traditional ventilation system gives very good results in controlling the smoke.

- Decreasing the number of supply fans will make the smoke spread rate inside the hangar lower.

\section{References}

1. National Fire Protection Association. NFPA 130,"Standard for Fixed Guide way Transit System", 2003.

2. http://blog.envenio.com/aircraft-hangar-hvac-cfdsimulation, 2017 .

3. "British Standard for smoke and heat control systems “,BS $734-7: 2006$

4. K.M.Bulter and G.W.Mulholl. " Generation and transport of smoke components. " Fire Technology Vol. $40, \quad$ p.149-176, 2004.

5. http://www.cairo.climatemps.com/ (06.18.2018).

6. L.H.Hu, N.K. Fong, L.Z. Yang, W.K., Chow ,Y.Z. Li, R. Huo, "Modeling fire-induced smoke spread and carbon monoxide transportation in a long channel: Fire Dynamics Simulator comparisons with measured data".Journal of Hazardous Materials Vol.140p.293-298.2007.

7. L.H.Hu, N.K. Fong, L.Z. Yang, W.K., Chow ,Y.Z. Li, R. Huo, Corrigendum to "Modeling fire-induced smoke spread and carbon monoxide transportation in a long channel: Fire Dynamics Simulator comparisons with measured data". Journal of Hazardous Materials Vol.140 p. 293-298.2007. 